Çukurova Üniversitesi Mühendislik Mimarlık Fakültesi Dergisi, 32(4), ss. 31-38, Aralık 2017

Çukurova University Journal of the Faculty of Engineering and Architecture, 32(4), pp. 31-38, December 2017

\title{
Çukurova Bölgesi Kireçtaşlarının Los Angeles Aşınma Direnci ile Fiziko-Mekanik Özellikleri Arasındaki İlişkinin İncelenmesi
}

\author{
Ahmet Mahmut KILIÇ ${ }^{1}$, Esma KAHRAMAN ${ }^{* 1}$ \\ ${ }^{1}$ Çukurova Üniversitesi, Mühendislik Mimarlık Fakültesi, Maden Mühendisliği Bölümü, Adana
}

Geliş tarihi: 07.06.2017 Kabul tarihi: 19.12.2017

$\ddot{\mathbf{O z}}$

Kireçtaşları inşaat, kimya ve yapı malzemesi üretimi gibi pek çok sektörde yaygın olarak kullanılmaktadır. İnşaat ve yapı malzemesi üretiminde kullanılan kireçtaşlarının belirli standartlarda olması gereklidir. Kireçtaşlarının aşınma direnci bu standartlardan biridir. Los Angeles testi, aşınma direnci değerinin değerlendirilmesi için kullanılan en yaygın testlerdendir. Fakat bu test yönteminin zorlukları vardır. Bu çalışmada, Çukurova bölgesi kireçtaşlarının Los Angeles aşınma direnci, tek eksenli basınç dayanımı, su emme oranı, Shore sertliği ve özgül ağırlıkları belirlenmiştir. Deney sonuçları temel alınarak Los Angeles aşınma direnci ile diğer parametreler arasındaki ilişkiler Minitab 18 kullanılarak araştırılmıştır ve Los Angeles aşınma direnci ile fiziko-mekanik parametreler arasında anlamlı ilişkiler elde edilmiştir.

Anahtar Kelimeler: Minitab, Los Angeles aşınma direnci, Fiziko-mekanik özellikler

\section{Investigation of the Relationship between Los Angeles Abrasion Resistance and Physico-Mechanical Properties of Limestone in Cukurova Region}

\begin{abstract}
Limestone is one of the most basic raw materials used in many sectors such as construction, chemistry and building material production. Limestones used in construction and building material production must be in certain standards. Abrasion resistance of limestone is one of these standards. The Los Angeles test is the most common test used for assessment of abrasion resistance value. But, this test method has difficulties. In this study, Los Angeles abrasion resistance, uniaxial compressive strength, water absorption rate, Shore hardness and specific gravity were determined limestone samples in Cukurova Region. Relationships between Los Angeles abrasion and the other parameters were investigated on the basis of experimental results by using Minitab 18 and meaningful relationships were obtained between Los Angeles abrasion resistance and physico-mechanical parameters.
\end{abstract}

Keywords: Minitab, Los Angeles abrasion resistance, Physico-mechanical properties

"Sorumlu yazar (Corresponding author): Esma KAHRAMAN, ekahraman@cu.edu.tr 


\section{GíRiş}

Kireçtaşları ülkemizde yaygın olarak bulunmakta olup genellikle beton agregası ve asfalt malzemelerinin ana hammaddesi olarak kullanılmaktadır. Kireçtaşlarının bu alanda kullanılmaları için fiziksel ve mekanik özellikleri açısından bazı standartları sağlaması gerekmektedir. Yapıların sağlamlığı ve yolların kalitesi tamamen bu özelliklere bağlıdır.

Aşınma direnci agregaların önemli bir özelliğidir ve genel olarak çelik küreler tarafindan darbe ve ezilme nedeniyle kaya parçacıklarının yıpranması sırasında agreganın aşınmaya direncini ölçen Los Angeles (LA) testi kullanılarak saptanmaktadır. Kayaçların aşınmaya ve ayrışmaya karşı dayanımlarının belirlenebilmesi için çeşitli deney yöntemleri önerilmiştir. Bunlardan bazıları şu şunlardır [1];

- Los Angeles aşınma deneyi,

- Mikro-Deval aşınma deneyi,

- Nordik Bilya Değirmeni deneyi,

- Magnezyum sülfat dayanımı deneyi

- Sodyum sülfat dayanımı deneyi

- Darbe dayanım deneyi olarak sıralanabilir.

Yaşar ve Yılmaz [1] yaptıkları çalışmada kayaçların aşınma dayanım tayininde Mikro-Deval yöntemini kullanarak mekanik özellikleri ilişkilendirmişler ve Mikro-Deval aşınma değeri ile inceledikleri mekanik özellikler arasında ilişkiler elde etmişlerdir.

Ballivy ve Dayre [2] farklı kireçtaşı numuneleri üzerinde gerçekleştirdiği deneyler sonucunda basınç dayanımı ve LA aşınma direnci arasında ters bir ilişki bulmuşlardır. Farklı kireçtaşı türlerinde korelasyon derecesinin farklılık gösterdiğine işaret etmişlerdir. Gözenekli kireçtaşlarının güçlü bir korelasyon gösterdiğini ve masif, daha az gözenekli olanların ise korelasyonun değiştiğini vurgulamışlardır.

Kahraman ve arkadaşları [3] kayaçların darbe dayanımı indeksini ve kayaçların tek eksenli basınç dayanım değerini kullanarak LA aşınma direncini tahmin etmişlerdir.
Özçelik [4] yaptığı araştırmada farklı kökenli kayaçların LA aşınma direnci ile fiziksel ve mekanik özelliklerini ilişkilendirmiştir.

Kahraman ve Günaydın [5] 35 farklı kaya türünü kullanarak agrega aşınma direncini tahmin etme imkanını araştırmışlardır. Yaptıkları deneyler sonucunda elde ettikleri LA aşınma testlerinin sonuçlarını, Schmidt çekici sertliği ve nokta yük dayanımı testlerinin sonuçlarını istatistiksel olarak kıyaslamışlardır.

Kazi ve Al-Mansour [6] Suudi Arabistan Cidde bölgesindeki farklı kayaç türleri üzerinde yaptıkları çalışmada LA aşınma direnci ile Schmidt sertliği arasında ampirik bir ilişki kurmuştur.

LA aşınma direnci uygulamada basit görünmesine rağmen, bazı diğer fiziksel testlere kıyasla zaman alıcı, iş gücü gerektirici ve pahalıdır. Bundan dolayı bu çalışmada uygulaması daha kolay olan Shore sertliği, tek eksenli basınç dayanımı, su emme oranı ve özgül ağırlık ile LA aşınma direnci arasında ilişki kurulmaya çalışılmıştır. Böylelikle bu çalışma ön incelemelerde bize yol gösterecek ve kolaylık sağlayacaktır.

\section{MATERYAL VE METOT}

Günümüzde doğal taşların beton agregası olarak kullanılabilmesine karar verebilmek için bir takım fiziko-mekanik parametrelerin belirlenmesi gerekmektedir. Kireçtaşı numuneleri üzerinde gerçekleştirilen fiziksel ve mekanik deneyler TS 699/T1 [7] 'Doğal yapı taşları inceleme ve laboratuvar deney yöntemleri' standardına göre belirlenmiştir. Deney sonuçları Minitab 18 paket programı kullanılarak istatistiksel olarak değerlendirilmiştir.

\subsection{Materyal}

$\mathrm{Bu}$ çalışmada Çukurova bölgesinde farklı bölgelerden elde edilen kireçtaşı agregaları kullanılmıştır (Şekil 1). Farklı bölgelerden alınan numuneler laboratuara getirilmiş ve deney prosedürüne uygun olarak hazırlanmışlardır. 
Toplamda 29 farklı numune alınmıştır. Makro boyutta numuneler üzerinde yapılan incelemelerde;

1-6 numaralı numuneler: Osmaniye bölgesinden alınmıştır. Koyu gri renkli kırıklı ve çatlaklı bir yapıya sahiptir.

7-11 numaralt numuneler: Ceyhan bölgesinden alınmıştır. Numuneler incelendiğinde ince kristalin bir yapıda olduğu görülmektedir. Örnekler açık, mavimtırak ve gri renklidir. Gözenekliliği düşüktür. Kireçtaşları, bölgenin fay kırıkları ile çevrili olması nedeni ile bol çatlaklı, bazı fay çatlaklarının arası kil dolguludur.

12-14 numaralı numuneler: Kozan bölgesinden alınmıştır. Gri, mavimtrak renkli, kırıklı bir yapıya sahip olup, çatlaklar içerisinde demir alterasyonu mevcuttur.

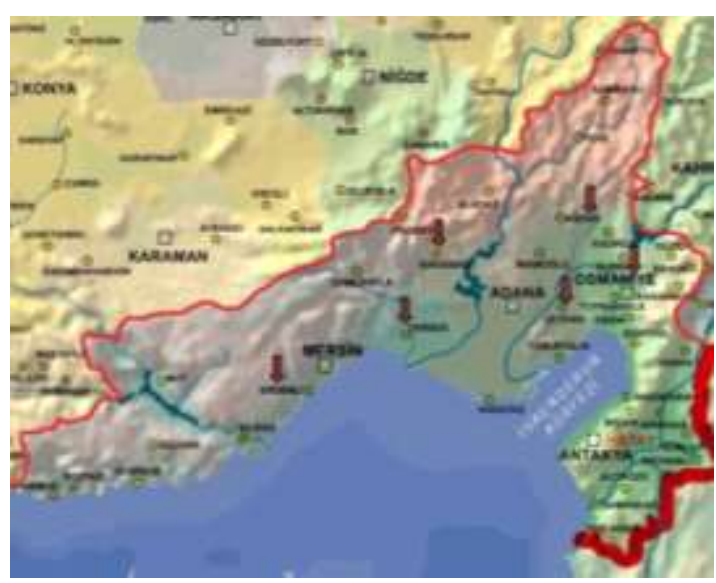

Şekil 1. Kireçtaşı numunesi alınan bölgeler

15-18 numaralı numuneler: Karaisalı bölgesinden alınan numuneler incelendiğinde diğer örneklere göre daha az kırıklı ve boşluk oranının da oldukça düşük olduğu görülmüştür. Rengi çok açık, sarımsı gridir. Genellikle masiftir. Kırıklı yüzeylerde demir alterasyonu görülmektedir.

19-24 numaralı numuneler: Tarsus bölgesinden alınan numuneler; fosilli, beyaz-krem renkli, az boşluklu, genellikle masif görünümlü kireçtaşından oluşmaktadır.
25-29 numaralt numuneler: Erdemli bölgesinden alınan numuneler krem-açık gri renkli olup daha sert yapıdadır. Boşluk oranı oldukça azdır. Ara ara fosilleşme gözlenmektedir.

\subsection{Metot}

Farklı bölgelerden alınan numuneler üzerinde LA aşınma direnci, Shore sertliği, özgül ağırlık, su emme ve tek eksenli basınç dayanımı deneyleri uygulanmıştır.

Los Angeles Assınma Direnci: LA aşınma direnci deneyi darbe sonucu agreganın ufalanmasının ölçümü deneyidir. Deney TS EN 1097-2/D1 [8]'e uygun olarak yapılmıştır. Şekil 2'de LA aşınma direnci test cihazı görülmektedir.

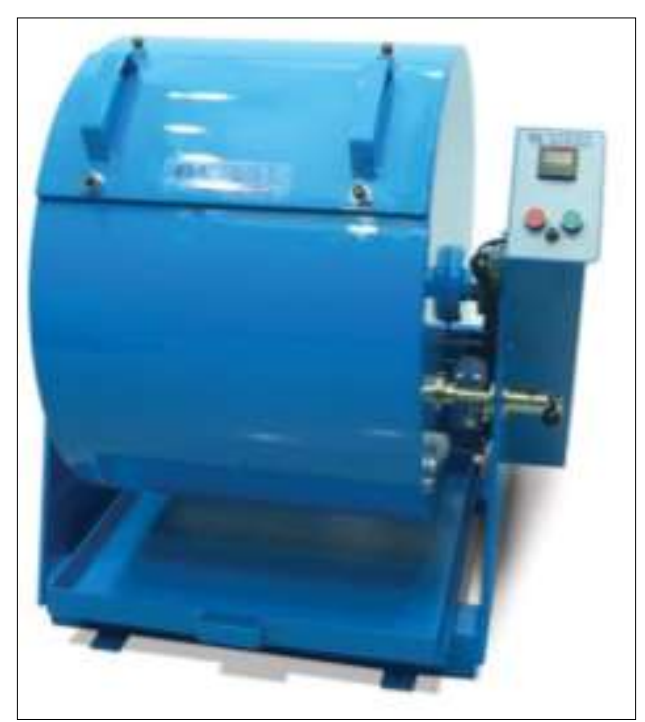

Şekil 2. LA aşınma direnci test cihazı [9]

Shore Sertliği: Kayaçların fiziksel özelliklerinden biri olan sertlik temel olarak kayacın mineralojisinden, bağlayıcı madde özelliklerinden, matrix tipinden ve elastisitesinden etkilenmektedir [10].

Shore sertliği tane boyutu $0,2 \mathrm{~mm}$ 'den büyük kayaçlar için sert minerallerin yüzdesinin hızlı ölçümünü ortaya koymak için kullanılabilmekte ve kayaç mineralojisi ile doğrudan ilişkisi bulunmaktadır [11]. 
Shore sertliği ölçümünde araştırmacılar tarafindan farklı deney boyutları önerilmektedir [12-15]. Sertlik ölçümlerinde Shore Sceleroscope'u kullanılmaktadır. Numuneler üzerinde ISRM [13]'de belirtilen ölçüm prensipleri uygulanmıştır.

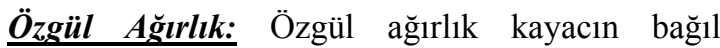
yoğunluğunun ölçümü ile ilgilidir. Numuneler 0,2 mm'lik eleklerden geçecek şekilde öğütülmüş ve TS EN 1097-6 [16] standardına uygun olarak deney prosedürü uygulanmıştır.

Su Emme Oranı: Ağırlıkça su emme deneyi kayaç örneklerinin ağırlıklarına oranla, boşlukların alabileceği su miktarının saptaması amacıyla yapılır [17]. Deney numunesi olarak 4 cm'lik küp numune kullanılmış ve TS EN 1097-6 [16] standardina uygun olarak deney gerçekleştirilmiştir.

Tek Eksenli Basınc Dayanımı: Basınç dayanımı, belirli bir yüke karşı kayaçların kırılmadan önceki maksimum dayanabilme yeteneği olarak tanımlanmaktadır. Deney numunesi olarak karot numuneleri hazırlanmıştır.

Deney TS 699/T1 [7] standardına uygun olarak gerçekleştirilmiştir ve deneyde ELE marka elektronik hidrolik pres kullanılmıştır. Pres yardımıyla numune üzerine düşey olarak yük uygulanmış ve uygulanan yük ölçülmüştür.

\section{ARAŞTIRMA BULGULARI}

Çukurova bölgesinden elde edilmiş 29 farklı numune üzerinde LA aşınma direnci, Shore sertliği, özgül ağırlık, su emme oranı, tek eksenli basınç dayanımı deneyleri uygulanmış ve deney sonuçları kullanılarak değişkenler arasında ilişki kurulmuştur. İstatistiksel analizler Minitab 18 programı kullanılarak yapılmıştır.

\subsection{Basit Regresyon Analizi Sonucları}

Her bir bağımsız değişken için basit regresyon analizleri yapılmış ve ilişki kurulmuştur. Bağımsız değişken tarafından açıklanan bağımlı değişkendeki değişim oranı $\mathrm{R}^{2}$ kullanılarak değerlendirilmiştir. 1 'e yakın olan $\mathrm{R}^{2}$ değeri bağımlı değişkendeki değişkenliğin çoğunu regresyon modeli tarafından açıklandığını gösterir.

Çukurova bölgesinde üretilen kireçtaş1 agregalarının LA aşınma direnci ile Shore sertlik değerleri arasındaki ilişki değerlendirilmiştir (Şekil 3). Değişkenler arasındaki ilişkinin kuvvetindeki değişimi açıklama oranı yani $\mathrm{R}^{2}$ değeri 0,851 olarak bulunmuştur. Hata kareleri ortalaması ise 1,712 olarak belirlenmiştir. Ayrıca Shore setliğini kullanarak LA aşınma direnci tahmini için oluşturulan eşitlikte grafik üzerinde verilmiştir.

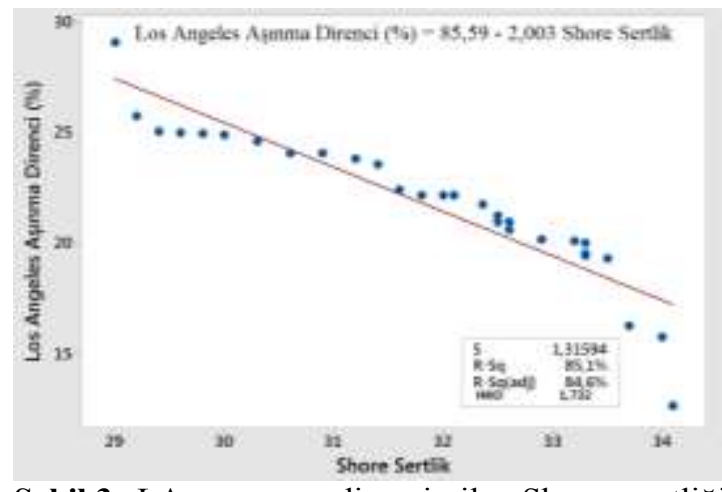

Şekil 3. LA aşınma direnci ile Shore sertliği arasındaki ilişki

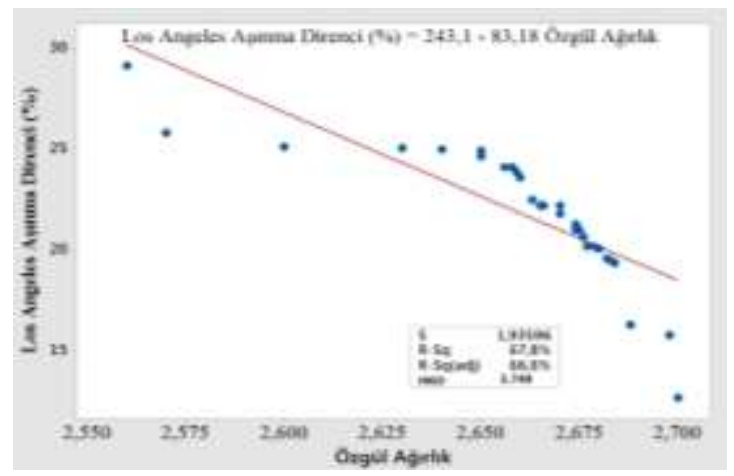

Şekil 4. LA aşınma direnci ile özgül ağırlık arasındaki ilişki

LA aşınma direnci ile özgül ağırlık verileri incelendiğinde iki değişken arasındaki ilişkinin kuvvetindeki değişimi açıklama oranı yani $\mathrm{R}^{2}$ değeri 0,678 olarak bulunmuştur. $\mathrm{Bu}$ oranı destekleyen eşitlik grafik üzerinde belirtilmiştir 
(Şekil 4). Hata kareleri ortalaması ise 3,748 olarak belirlenmiştir. Çukurova bölgesi kireçtaşı agregalarının LA aşınma direnci değerleri ile su emme oranı arasındaki ilişki incelendiğinde iki değişken arasındaki ilişkinin kuvvetindeki değişimi açıklama oranı yani ilişkinin şiddetinin göstergesi olan $\mathrm{R}^{2}$ değeri 0,770 olarak bulunmuştur. Hata kareleri ortalaması ise 2,67 olarak değerlendirilmiştir (Şekil 5).

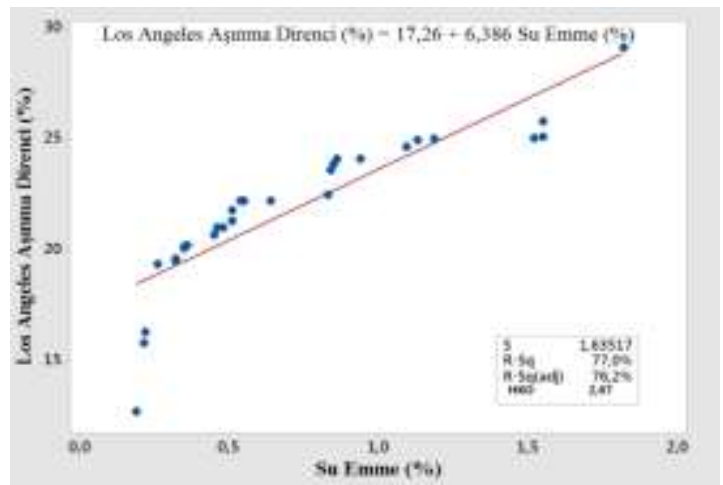

Şekil 5. LA aşınma direnci ile su emme oranı arasındaki ilişki

LA aşınma direnci değeri ile tek eksenli basınç dayanımı arasındaki ilişkinin kuvvetindeki değişimi açıklama oranı yani $\mathrm{R}^{2}=0,885$ olarak bulunmuştur. Hata kareleri ortalaması ise 1,343 olarak belirlenmiştir. Ayrıca LA aşınma direncinin tahmini için tek eksenli basınç dayanımı kullanılarak oluşturulan eşitlikte grafik üzerinde verilmiştir (Şekil 6).

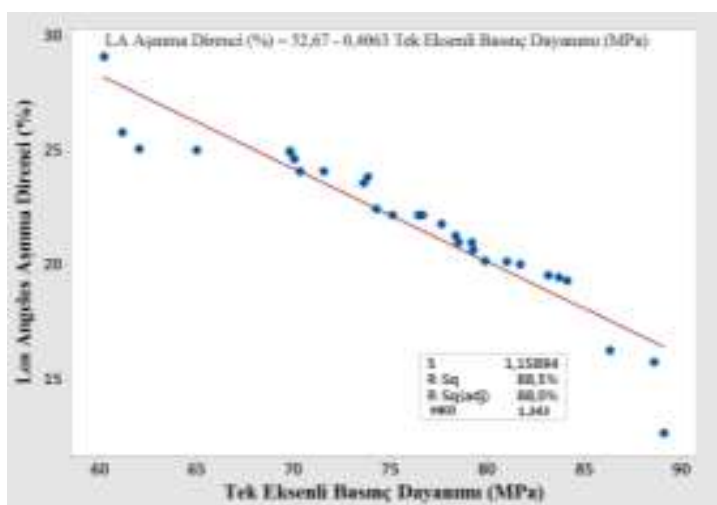

Şekil 6. LA aşınma direnci ile tek eksenli basınç dayanımı arasındaki ilişki

\section{2. Çoklu Regresyon Analizi Sonuçları}

LA aşınma direncinin tüm bağımsız değişkenlerle olan ilişkisini belirlemek amacıyla çoklu regresyon analizi yapılmıştır. Analiz sonucunda LA aşınma direncinin diğer dört değişken ile (Shore sertliği, özgül ağırlık, su emme ve tek eksenli basınç dayanımı) arasında ilişki kurulmuş ve ilişki sonunda LA aşınma direnci tahmini eşitliği oluşturulmuştur (Şekil 7).

Eşitlik kullanılarak elde edilen sonuçlar yani tahmin edilen sonuçlar ile ölçülen sonuçlar karşılaştırılmıştır. İki değer arasındaki ilişkinin kuvvetindeki değişimi açıklama oranı $\mathrm{R}^{2}$ değeri 0,912 olarak belirlenmiş, hata kareleri ortalaması ise 1,025 bulunmuştur (Şekil 7). LA aşınma direnci ölçülen değerleri, tahmin edilen değerleri ve farkları Çizelge 1'de verilmiştir.

Çizelge 1. Ölçülen ve tahmin edilen LA aşınma direnci değerleri ve arasındaki farklar

\begin{tabular}{|c|c|c|c|}
\hline & $\begin{array}{c}\text { Hesaplanan LA } \\
\text { Aşınm Direnci } \\
\mathbf{( \% )}\end{array}$ & $\begin{array}{c}\text { Tahmin Edilen LA } \\
\text { Aşıma Direnci } \\
\mathbf{( \% )}\end{array}$ & Fark \\
\hline $\mathbf{1}$ & 29,12 & 26,8136 & 2,30635 \\
\hline $\mathbf{2}$ & 25,80 & 27,6447 & $-1,84474$ \\
\hline $\mathbf{3}$ & 25,10 & 27,0239 & $-1,92392$ \\
\hline $\mathbf{4}$ & 25,04 & 25,4015 & $-0,36155$ \\
\hline $\mathbf{5}$ & 25,00 & 24,4774 & 0,52264 \\
\hline $\mathbf{6}$ & 24,94 & 24,6057 & 0,33430 \\
\hline $\mathbf{7}$ & 24,65 & 24,4166 & 0,23336 \\
\hline $\mathbf{8}$ & 24,10 & 24,8342 & $-0,73419$ \\
\hline $\mathbf{9}$ & 24,10 & 24,3132 & $-0,21317$ \\
\hline $\mathbf{1 0}$ & 23,86 & 22,8478 & 1,01219 \\
\hline $\mathbf{1 1}$ & 23,60 & 22,8241 & 0,77592 \\
\hline $\mathbf{1 2}$ & 22,48 & 22,3366 & 0,14336 \\
\hline $\mathbf{1 3}$ & 22,20 & 22,7492 & $-0,54919$ \\
\hline $\mathbf{1 4}$ & 22,20 & 22,3400 & $-0,13999$ \\
\hline $\mathbf{1 5}$ & 22,20 & 22,1918 & 0,00816 \\
\hline $\mathbf{1 6}$ & 21,80 & 21,5675 & 0,23253 \\
\hline $\mathbf{1 7}$ & 21,30 & 21,0334 & 0,26657 \\
\hline $\mathbf{1 8}$ & 21,00 & 21,1251 & $-0,12510$ \\
\hline $\mathbf{1 9}$ & 21,00 & 20,7808 & 0,21918 \\
\hline $\mathbf{2 0}$ & 20,67 & 20,7892 & $-0,11919$ \\
\hline $\mathbf{2 1}$ & 20,20 & 20,6743 & $-0,47434$ \\
\hline $\mathbf{2 2}$ & 20,16 & 19,8204 & 0,33962 \\
\hline $\mathbf{2 3}$ & 20,06 & 19,3806 & 0,67942 \\
\hline $\mathbf{2 4}$ & 19,58 & 18,7335 & 0,84653 \\
\hline $\mathbf{2 5}$ & 19,49 & 18,4384 & 1,05157 \\
\hline $\mathbf{2 6}$ & 19,35 & 18,3441 & 1,00591 \\
\hline $\mathbf{2 7}$ & 16,30 & 17,1753 & $-0,87533$ \\
\hline $\mathbf{2 8}$ & 15,80 & 15,6746 & 0,12541 \\
\hline $\mathbf{2 9}$ & 12,70 & 15,4423 & $-2,74230$ \\
\hline & & & \\
\hline
\end{tabular}




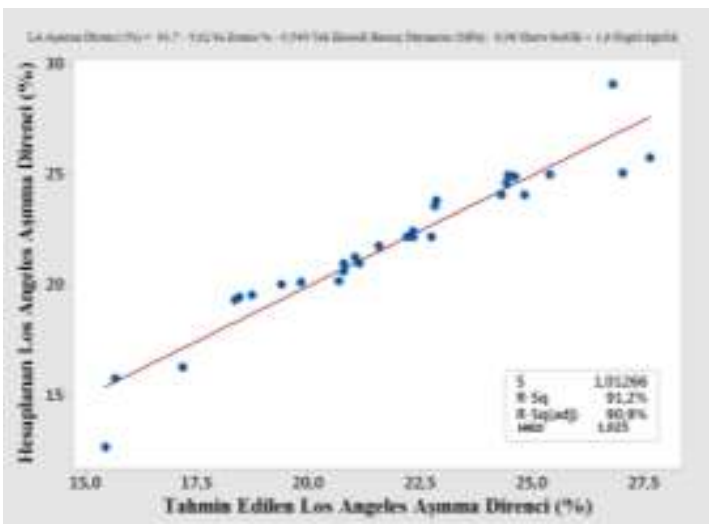

Şekil 7. Ölçülen LA aşınma direnci değerleri ile tahmin edilen LA aşınma direnci değeri arasındaki ilişki

\section{SONUÇLAR}

$\mathrm{Bu}$ çalışmada, Çukurova bölgesinde bulunan 29 farklı kireçtaşı agregası üzerinde Shore sertliği, özgül ağırlık, su emme oranı ve tek eksenli basınç dayanımı ve LA aşınma direnci deneyleri yapılmıştır. Elde edilen deney sonuçları ile LA aşınma kaybı tahmini için basit ve çoklu regresyon yapılmıştır. Regresyon modelleri; bağımlı değişken ile bağımsız değişkenler arasında güçlü bir ilişki olduğunu göstermiştir. Ayrıca LA aşınma direnci tahmini için amprik formüller üretilmiştir. Yapılan analizler ile elde edilen grafiklere göre LA aşınma direnci aşağıda verilen doğruluk oranları ile hesaplatılabilmektedir.

- Shore sertlik oranından LA aşınma direnci $\% 85,1$

- Özgül ağırlık değerinden LA aşınma direnci $\% 67,8$

- Su emme oranında LA aşınma direnci $\% 77$

- Tek eksenli basınç dayanımı değerinden LA aşınma direnci \%88,5

Ayrıca çoklu regresyon analizi incelendiğinde Çukurova bölgesi kireçtaşı agregalarında Shore sertlik oranı, özgül ağırlık değeri, su emme oranı ve tek eksenli basınç dayanımı değeri kullanılarak LA aşınma direnci değeri \%90,9 doğruluk oranı ile hesaplatılabilecektir. Bu değer bize yüksek bir ilişkinin varlığını göstermektedir.
Sonuç olarak, LA aşınma direnci deneyinin yapılmadığı koşullarda LA aşınma direnci Shore sertliği, özgül ağırlık, su emme ve tek eksenli basınç dayanımı değerleri kullanılarak tahmin edilebileceği kanaatine varılmıştır. Böylelikle LA aşınma direnci değeri daha kısa zamanda ve daha az iş gücü kullanarak tespit edilebilecektir.

\section{KAYNAKLAR}

1. Yaşar, S., Yılmaz, A.O., 2015. Kayaçların Mikro-Deval Aşınma Değeri ile Mekanik Özelliklerinin Karşılaştırılması, 7. Ulusal Kırmataş Sempozyumu, İstanbul.

2. Ballivy G., Dayre M., 1984. The Mechanical Behaviour of Aggregates Related to Physicomechanical Properties of Rocks. Int Assoc Eng Geol Bull 29, 339-342.

3. Kahraman, S., Günaydın, O., Fener, M., 2009. Kayaçların Los Angeles Aşınma Kaybının Darbe Dayanımı İndeksinden Tahmin Edilmesi. 5. Ulusal Kırmataş Sempozyumu, 131-136, İstanbul.

4. Özçelik, Y., 2011. Predicting Los Angeles Abrasion of Rocks from Some Physical and Mechanical Properties. Sci. Res. Ess., 67, 1612-1619.

5. Kahraman, S., Gunaydın, O., 2007. Empirical Methods to Predict the Abrasion Resistance of Rock Aggregates. Bull. Eng. Geol. Env., 66, 449-455.

6. Kazi, A., Al-Mansour, L.R., 1980. Empirical Relationship between Los Angeles Abrasion and Schmidt Mammer Strength Tests with Application to Aggregate Around Jeddah. Q.J. Eng. Geol., 13, 45-52.

7. TS 699/T1, 2016. Doğal Yapı Taşları-İnceleme ve Laboratuvar Deney Yöntemleri, Ankara.

8. TS EN 1097-2/D1, 2016. Agregaların Mekanik ve Fiziksel Özellikleri için Deneyler-Bölüm 2: Parçalanma Direncinin Tayini için Yöntemler, Ankara.

9. http://www.utest.com.tr/tr/20389/Los-AngelesAsindirma-Cihazi, Erişim tarihi: 10.05.2017

10. Gündüz, L., Entürk, A., Tosun, Y., Sarışı, A., 1996. Mermer Teknolojisi, Tura Ofset, Süleyman Demirel Üniversitesi Mühendislik Fakültesi, Isparta. 
11. McFeat-Smith, I., 1977. Rock Property Testing for the Assessment of Tunnelling Machine Performance, Tunnels and Tunnelling, 29-33.

12. Misra B., 1972. Correlation of Rock Properties with Machine Performance, Ph.D. Thesis, University of Leeds.

13. ISRM, 1981. Commission on Standard Isation Laboratory and Field Results, Suggested Methods for Determining Hardness and Abrasiveness of Rocks, Int. J. Rock Mech. Min. Geomech. Abstr., 15, 89-97.

14. Rabia, H., Brook, N., 1979. The Shore Hardness of Rock, Technical Note, Int. J. Rock Mech. Min. Geomech. Abstr., 16, 335-336.

15. Altındağ, R., 2002. Effects of Specimen Volume and Temperature on Measurements of Shore Hardness, Technical Note, Rock Mech. Rock Engng., 35(2), 109-113.

16. TS EN 1097-6, 2013 Agregaların Mekanik ve Fiziksel Özellikleri için Deneyler-Bölüm 6: Tane Yoğunluğunun ve $\mathrm{Su}$ Emme Oranının Tayini, Ankara.

17. Teymen, A., 2005. Bazı Kayaçların Petrografik, Fiziksel ve Mekanik Özelliklerinin İncelenmesi, Yüksek Lisans Tezi, Çukurova Üniversitesi, 136, Adana. 
